\title{
Overview of principles and implementations to deal with spatial issues in monitoring environmental effects of genetically modified organisms
}

\author{
Winfried Schröder ${ }^{\dagger}$ and Gunther Schmidt ${ }^{*}$
}

\begin{abstract}
The approval of genetically modified organisms [GMO] for deliberate release and placing on the market requires GMO environmental risk assessment [ERA] and GMO environmental monitoring [EM]. Both GMO ERA and GMO EM are still under discussion. The goal of this article is, firstly, to analyse principles of GMO EM as published in the Association of German Engineers [VDI] Guideline 4330 Part 1, focusing on the characterisation of the receiving environment affected by GMO cultivation and the representativeness of GMO EM to assess large-scale implications of GMO cultivation. Secondly, the article introduces measures to meet these issues by the use of map data and statistics within a geographical information system [GIS]. Finally, three case studies exemplify the application of data and methods. To deal with spatial issues of GMO EM as outlined in the VDI Guideline 4330 Part 1, a GIS-based approach is presented. It relies on both spatial data collected from several sources which were derived from sample point data and geostatistical and multivariate statistical methods within a GIS environment. Data used for describing the receiving environment and for planning and evaluating monitoring schemes comprise information about land use, climate, phenology, soil coverage, species distribution and ecoregions. The case studies deal with (1) ecological land classification for characterisation of GMO-receiving environments and representative EM, (2) selection of representative sites for modelling GMO dispersal, and (3) delineation and mapping of segregation distances. Even a systematic and stepwise-structured risk assessment cannot cover all risk relevant questions, especially large-scale, long-term and combinatory effects which may not occur before the conventional application of the respective GMO. Hence, GMO EM is crucial to deal with unanticipated and undesirable effects. The article gives an overview of a GIS implementation and relevant geodata promoting GMO EM.
\end{abstract}

\section{Background}

In the European Union [EU], the release of genetically modified organisms [GMO] into the environment is regulated by EU Directive 2001/18/EC [1]. Accordingly, post-market environmental monitoring of genetically modified plants [GMP EM] has to be implemented to detect and prevent adverse effects on human health and the environment. However, no general strategies for GMP EM have been established so far. In Germany, one EM strategy discussed is the Guideline 4330 Part 1

\footnotetext{
* Correspondence: gschmidt@iuw.uni-vechta.de

† Contributed equally

Chair of Landscape Ecology, Universität Vechta, PO Box 15 53, Vechta, 49364, Germany
}

published by the Association of German Engineers [VDI] [2]. It applies to the monitoring of ecological effects of GMP, but does not address possible effects of GMP on human health. Contrary to the directive of the European Community [1] and the study of Sanvido et al. [3], the guideline of the VDI [2] does not differentiate between case-specific monitoring [CSM] and general surveillance [GS]. CSM should focus on anticipated effects of a specific GMP based on pre-market risk assessment, whereas GS is designed to detect unanticipated adverse effects which were not covered by risk assessment comprising, for instance, cumulative and long-term effects. 
The VDI [2] covers ecological effects of GMP encompassing direct, indirect, immediate and delayed as well as cumulative long-term effects. Environmental effects of GMP can occur on several levels of ecological organization in terms of structures and underlying functions, and correlated levels of time and space which have to be covered by GMP EM [4]. The VDI [2] provides planning and implementation criteria for GMP EM and forms the framework for technical instructions with respect to the levels mentioned above, items to be protected, protection targets and checkpoints. GMP EM should allow evaluating the condition of the items to be protected and to track the accomplishment of protection targets. The required parameters have to be collected using validated and standardised methods.

Since protection targets and checkpoints may not only be influenced by GMP, it is necessary to differentiate between GMP-related effects and those that are not related to GMP. Accordingly, data on items to be protected and protection targets without influence of GMP must also be compiled. To reach this requirement, temporal and spatial comparisons are needed: The environmental baseline status prior to the introduction of GMP has to be compared to the situation after GMP release regarding the selected checkpoints. The reliability of reference data depends on the period within the reference conditions were monitored before introducing GMP (temporal comparison). Additionally, GMP-free regions have to be compared to those where GMP are cultivated. This requires a reference system where both conditions are monitored simultaneously (spatial comparison). Reference sites should be as similar as possible to GMP-influenced areas considering the receiving agricultural environment. GMP areas and reference areas, however, can also be subjected to changes that are not caused by GMP. Thus, a thorough selection of monitoring areas is essential for monitoring potential ecological effects due to GMP cultivation. Besides the GMP fields and their surroundings, representative types of ecosystems that will potentially be affected should be considered as well. EM areas should be selected using a statistically substantiated procedure according to technically suitable representation criteria. The EM areas should be linked to other appropriate EM networks. In the long term, spatial rearrangement of EM areas is necessary regarding new effect relationships and spatial arrangement of land use patterns.

The GMP EM measuring data should be analysed on the basis of metadata describing them and by suitable (geo)statistical procedures. The documentation of measured variables, methods, survey intervals and areas must be carried out according to standard methods and using a main meta-database or several interrelated databases. Meta-databases should help evaluate on to what extent the data records can be compared with one another for assessment.

Based on the basic considerations as laid down in the guideline of the VDI [2] and summarised above, some research projects aimed at dealing with GMP EM at a landscape level and at developing techniques for supporting the application of the respective EM strategies. In the following, we refer to some of the respective methods and results and, thereby, concentrate on the setting in Germany as an example.

\section{Methods and data}

The following sections contain an overview of procedures implemented in a geographic information system [GIS] including geostatistics, multivariate statistics and geodata to (1) characterize the GMP-receiving environment, (2) to assess the spatial representativeness of GMP EM sites and (3) to assess large-scale and longterm effects of GMP cultivation. In Germany, several research projects dealt with these issues, and some of the methods applied and results achieved are outlined. It is shown that geodata are useful to describe the receiving environment in the near and far vicinities of GMP fields. Statistical analyses and classification of geodata are presented which serve to derive ecoregions, e.g. climatic and agricultural patterns and, thereby, help for assessing the representativeness of running or planned GMP EM sites and for investigating adverse ecological effects of GMP release on different spatial scales and for different agricultural regimes [5-11].

Geostatistics is a point-pattern analysis that generates surface predictions from data points. This relies on investigating and modelling the spatial autocorrelation among sample data by variogram analysis. In order to apply kriging for interpolation, it is necessary to adapt a defined variogram model to the experimental variogram. Based on the variogram model, several kriging methods can be used for spatial predictions which finally are mapped [12]. For the interpretation of the kriging estimations, a cross-validation has to be performed.

Multivariate statistics such as cluster analysis or treebased models, two of them are the classification and regression trees [CART] and chi-squared automatic interaction detection (CHAID), serve to spatially differentiate the multiple relationships between geodata stored in a GIS. Based on these relations, predictions in time and space become possible as well as the characterisation of the receiving environment in terms of ecoregions [13-18]. In the context of GMP dispersal, cluster analysis can be used to integrate measurement data from different meteorological networks with different coverage in a GIS environment for defining representative climatic regions. Climatic regions together with an ecological land classification were used to stratify the 
receiving environment in order to select a representative number of sites for modelling the GMP dispersal [10].

Geodata on meteorology, land use, local biodiversity and agricultural management schemes are needed for monitoring and modelling dispersal and persistence of GMP as well as planning GMP EM with respect to coexistence issues in agricultural landscapes. The data described in the following have been collected from several sources or have been calculated from sample point data by the use of the above mentioned statistical methods in a GIS environment described by Kleppin et al. [19].

Land use data can be obtained from either satellite images, GIS data collected during field experiments, cadastral surveys provided by local land registries, vertical air photographs or the Common Agricultural Policy notifications, each type of source being used at different scales and consequently provide different spatial and semantic resolutions. To some extent, data on field geometries providing detailed information on agricultural land use can be obtained from the Integrated Administration and Control System (InVeKoS) database, which is an important tool for the EU member states to regulate agricultural subsidies. In fact, due to legal restrictions and inconsistencies in data harmonisation which is due to federal responsibilities, this dataset is not available for public use [9]. Based on satellite images, data on land use patterns are offered by the European Topic Centre on Land Use and Spatial Information [20], where the distribution of the CORINE Landcover maps is administrated [21]. Data on the cultivation of crops in Europe are available at the Statistical Office of the European Communities [22], which offers data on various topics, among of which is also agriculture. The main cropping areas of oilseed rape are located in northeast Germany as well as in the Alsace in France. In these regions, oilseed rape is cultivated on up to $25 \%$ of the arable land. Due to the increased cultivation of energy plants, it can be assumed that the cultivation of maize (biogas) and oilseed rape (biodiesel) will be intensified in the future. For Germany, it can be stated that in 2007 , there was an increase in maize cultivation of $9.6 \%$ and of $8.8 \%$ for oilseed rape cultivation compared to those in 2006.

For large-scale analyses of GMP impacts, meteorological data are needed. These are, for example, data on precipitation, air temperature, sunshine duration, the number of frost days and wind conditions. Climate affects the growth, persistence and dispersal of GM crops and their pollen and seeds. These data could be retrieved from meteorological stations, which are usually widespread in Europe. However, depending on the required climatic element (precipitation, air temperature, wind or solar radiation), the number of monitoring sites and, thus, the validity of assumptions based on these data are different. For example, in France, the spatial density of monitoring sites collecting data on precipitation is two times more dense than on temperature, four times more than on wind and ten times more than on solar radiation. In Germany, the number of meteorological monitoring sites differs quite more. The German Weather Service operates about 4,400 precipitation sites, but only 660 stations for air temperature and 220 for solar radiation. Therefore, interpolations or extrapolations may be necessary, covering the whole territory of a country. For Europe, free datasets with a resolution of 10 arc min (approximately $20 \times 20 \mathrm{~km}$ ) are available at the Climatic Research Unit (CRU) [23,24]. For modelling the pollen transport, phenological data on the flowering of GM crops should be considered, too. It should be taken into account that global warming might have changed the temperature-induced beginning of rape and maize bloom $[18,25]$. Furthermore, modelling pollen dispersal requires data on wind regimes. The dynamics of pollen transport can be described by compiling and processing data on wind direction and velocity. The wind direction influences the transport direction of the pollen and, thus, potential areas of exposure. Given a constant emission rate, the wind velocity affects the range and the transport speed of airborne pollen and leads to a dilution (stretching); as with higher wind velocities, a larger air volume passes the source surface, and the concentration per unit volume is reduced [26].

Data on soil texture and soil types are available from the Food and Agriculture Organization [FAO]: (1) the Digital Soil Map of the World (about $10 \times 10 \mathrm{~km}^{2}$ ) [27] and (2) the Harmonized World Soil Database (about $1 \times$ $1 \mathrm{~km}^{2}$ ) [28]. Data on the potential natural vegetation which can be used for ecological land classification can be obtained from the Federal Agency of Nature Conservation (BfN) in Germany [29]. The potential natural vegetation $[\mathrm{PNV}]$ map stratifies Europe into more than 700 PNV units. The PNV can be defined as the vegetation that could be established without human interference under present climatic and soil conditions and is an integral indicator for the ecological conditions in terrestrial ecosystems [16].

For biodiversity data in the detection of adverse effects on biodiversity, a link between GMP and biodiversity monitoring is imperative [30,31]. It has to be expected that due to a large-scale commercial use of GMP, adverse effects on biodiversity become substantial. Biodiversity monitoring schemes could provide information on potential threats induced by GMP. For instance, biodiversity monitoring is able to detect the potential invasiveness of GM crops and the potentially enhanced mortality of non-target organisms, and it may also draw a more general picture on potential effects on the 
countryside biodiversity. In Europe, several biodiversity monitoring networks exist due to the Convention on Biodiversity, which commits its signatory countries to identify and monitor national biodiversity. However, these monitoring networks are poorly connected, and data are usually available only on a local or national level [32], whereas the monitoring of birds and butterflies is well established over long periods in some European countries (e.g. > 30 years in the UK), allowing an assessment of changes at several trophic and geographical scales [33,34]; monitoring is not in the same quality established across taxonomic groups relevant for GMP EM. Only few larger scale monitoring schemes of plants exist [35]. As of September 2007, the EuMon database comprised 552 complete monitoring schemes covering approximately 4,000 species and 145 different habitat types and addresses of 239 monitoring coordinators and institutions. Furthermore, the database contains information on sampling methods.

Changes of biodiversity due to GMP cultivation must be extractable from the background noise of sampling variability and population fluctuations. This is only possible if a considerable amount of sites is frequently and accurately monitored and if reference areas, i.e. areas without potential influence of GMP, are monitored at the same time and with the same accuracy. Even though the EuMon database is the largest collection of metadata on biodiversity monitoring available, it is not comprehensive and might be confounded by biases in observation accuracy [36]. Besides the EuMon database, there are only few more data sources where information on biodiversity or distribution of plant species - that may, for instance, serve as crossbreeding partners of GMP may be obtained. The Global Biodiversity Information Facility [37] enables free and open access to biodiversity data worldwide via the Internet to support sustainable development. An information system was built to allow the linkage of diverse data types from disparate sources, promoting capacity building and catalysing development of analytical tools for improved decision-making. A special application concerning forest data and the distribution of forest tree species is available through the European Forest Genetic Resources Programme [38], which is a collaborative programme among European countries to promote conservation and sustainable use of forest genetic resources. There is information available describing the spatial distribution of about 40 tree species occurring all over Europe. Data are stored as JPEG files but also as shape files for usage within a GIS environment. DIVA-GIS [39] is a free and open-source GIS to generate and analyse worldwide maps on species distribution data. DIVA-GIS was developed at the International Potato Center [40]. In Germany, the Federal Agency for Nature Conservation (BfN) maintains the web application FloraWeb [41], where information on about 3,500 plant species are stored containing details on e.g. taxonomy, biology and spatial distribution of plants in Germany. An interactive web application illustrates the distribution of the PNV [29] in Germany. A Java applet allows mapping selected plant species in a spatial differentiation based on cadastre maps (scale 1 is 25,000; $\approx 11 \times 11 \mathrm{~km}^{2}$ ).

A crucial problem for spatial analyses is the availability of data on the distribution of present pests. For the federal state of Brandenburg, there were data collected on a district level regarding the spatial distribution of the European corn borer (Ostrinia nubilalis) which was one reason for the introduction of Bt maize. Figure 1 depicts the distribution of the corn borer in the federal state of Brandenburg for the years 2005, 2006 and 2007.

Some of the data and methods presented above have been used in several case studies which have been conducted according to selected aspects of the VDI Guideline 4330 Part 1 [2]. Three of them are summarised below: (1) ecological land classification for characterisation of GMP-receiving environments and representative EM, (2) selection of representative sites for modelling GMP dispersal and (3) delineation and mapping of isolation zones.

\section{Results and discussion}

Case study 1: ecological land classification for characterisation of the GMP-receiving environment and implementation representative EM

The VDI Guideline 4330 Part 1 [2], the German Federal Nature Protection Law (Section 6 of the Bundesnaturschutzgesetz), the environmental monitoring concept of the Federal Ministry for the Environment, Nature Conservation and Nuclear Safety [42] as well as the preamble of the administrative agreement between the German government and the federal states on the exchange of environmental data specify the following targets that should be complied with when carrying out environmental monitoring: The monitoring should be coordinated and based on harmonised or standardised methods [43] so that the data can be compared and used for statistical analysis and modelling. The monitoring data should allow for spatial extrapolation in order to bridge geographical gaps and for supporting longterm research on environmental changes. The flow of data should be efficient, and the data should be available for scientists, especially for statistical testing of hypotheses and modelling data. The latter aspect also implies important technical issues because of the enormous amount of information and data collected. For example, environmental monitoring networks require information exchange, which has to be supported by an adequate and efficient information platform that handles 


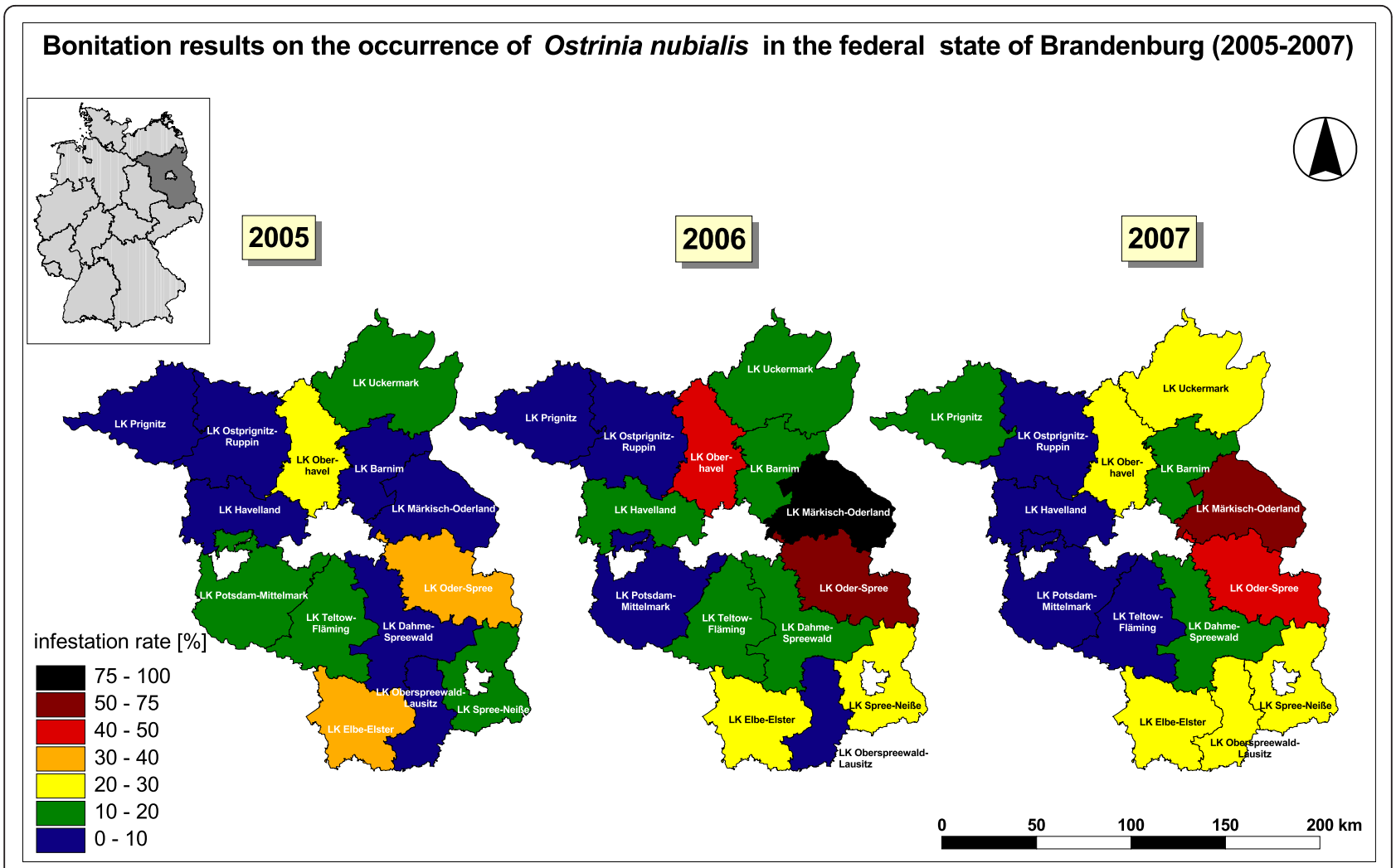

Figure 1 Distribution of the corn borer (O. nubilalis) in Brandenburg between 2005 and 2007. Mapping is based on data handed over by Dr. Werner Kratz, Landesumweltamt Brandenburg.

documentation and exchange of metadata (site descriptions, quality control data), measuring data and geodata. An appropriate tool to achieve these goals is the implementation of a web-based GIS that contains relevant geodata and offers tools for integration of information of related environmental monitoring networks and tools for data analysis. Such information platforms help in reducing GMP EM costs and enable data and information exchange between different stakeholders, involving farmers, legal authorities and the public.

Long-term and indirect effects of any new technology present a challenge to risk assessment. Post-release GMP EM provides mechanisms for the early detection of any adverse effects, but the challenge for scientific committees, applicants and regulators is to identify the key areas of uncertainty and to design appropriate monitoring and surveillance methods. Small plots and laboratory studies are unlikely to prove useful in such an evaluation. Therefore, appropriate large-scale monitoring, experimentation and modelling are needed to determine the impact on the landscape from GMP trait characteristics [44]. GMP monitoring should cover both the GMP concerned and the potential receiving environment. GMP ERA and EM should comprise the evaluation of the characteristics of the GMP and its effects and stability in the environment, combined with ecological characteristics of the environment in which the introduction will take place. Thus, EM of GMP impacts should be implemented regarding description, explanation and modelling of environmental changes potentially due to GMP cultivation.

The requirements mentioned above imply that the EM network should cover the ecologically defined land classes in the respective country without gaps by a statistically adequate number of EM sites. This ecological representativeness is crucial for the validity of the EM sampling data $[45,46]$. Thus, monitoring and modelling of GMP dispersal should be performed at locations which are representative for larger areas with respect to those factors which potentially influence the dispersal, as for instance natural land characteristics such as wind conditions. Following this concept, ecoregions can be used to extrapolate modelling results (up-scaling) calculated for specific agricultural and environmental conditions at single locations to those areas where similar conditions exist, i.e. regions belonging to the same ecoregion. Additionally, GMP EM should take place in areas exposed to GMP, preferably cultivated fields and their 
environment, but should also include regions with no or unknown GMP exposure as reference areas. On a case-bycase basis, depending on the GMP characteristics, the selected indicators, checkpoints and related analytical methods should consider different relevant spatial and temporal scales $[2,6]$. The number of monitoring sites and regions needs to be sufficient to support statistical analysis of results based on good scientific practice [47-49]. For each GMP monitoring, design and data analyses should be based on appropriate scales of space and time, and the quality and quantity of data should be representative and interpretable. Criteria for selecting monitoring sites and regions include representativeness of sites cultivated with specific GMP, with emphasis on regions repeatedly cultivated with GMP; representativeness of ecological regions containing the spectrum of relevant indicators; availability of sites already monitored within other environmental programmes; and areas with environmental conditions facilitating spread or survival of GMP $[4,50]$.

In order to check the representativeness of existing EM networks which might be appropriate for EM GMP or for establishing specific EM GMP networks, ecoregionalisations are appropriate measures. For Europe and Germany, ecological land classifications were calculated by means of multivariate statistics and based on digital maps depicting the spatial patterns of ecologically relevant land characteristics. For both Germany and some federal states, ecoregions were calculated by applying CART and using surface maps on climate, altitude, soil and potential natural vegetation $[6,16]$. The resulting maps have a spatial resolution of $2 \times 2$ and $1 \times 1 \mathrm{~km}^{2}$. The land classification calculated for Europe by means of CART [13] subdivides the whole territory into ecoregions mapped in a grid with a cell size of about $20 \times 20 \mathrm{~km}^{2}$. Data used for calculating the ecoregions are maps on the PNV [29], on altitude (Global Land One-kilometer Base Elevation/GLOBE) [51], on soil texture (Digital Soil Map of the World/DSMW) [27] as well as on monthly averages on air temperature, sunshine duration, relative humidity and precipitation (Global Climate Dataset CL 2.0) [23]. The PNV was set as the target variable, whereas the above mentioned maps on altitude, soil texture and climate were chosen as predicting variables. In order to obtain a concise amount of ecoregions, the most detailed map depicting the spatial pattern of about 200 ecoregions was reduced to 40 ecoregions (Figure 2). Each of them can be described statistically and by the use of annual course diagrams and histograms as it is demonstrated for selected ecoregions (D_7 to D_22) in Figure 3.

\section{Case study 2: selection of representative sites for modelling GMP dispersal}

For modelling pollen dispersal of genetically modified oilseed rape [GM OSR], representative locations should be determined $[5,10]$. Accordingly, a method was developed that includes both the determination of representative OSR locations for modelling the dispersal at a field scale and the subsequent generalisation of the modelling result to the landscape level at a regional scale (up-scaling). Accordingly, land characteristics which are relevant for dispersal and persistence of GM OSR were regionalised within a GIS environment. The beginning of flowering of OSR was mapped by means of geostatistics. The resulting maps were used to select satellite images for the detection of OSR fields and to determine the period for the individual-based modelling. The monthly means (1961 to 1990) of precipitation [P], air temperature $[\mathrm{T}]$ and sunshine duration $[\mathrm{S}]$ were regionalised by the Ward cluster analysis [52], which has a wide range of applications in landscape ecology [53-55]. The PTS clusters were combined to four climatic regions which, together with Ward clusters on wind speed and direction as well as with land use clusters (crop rotation and management) [56], enabled to define eight regions in Northern Germany with a maximum of internal homogeneity. A distinct meteorological station was selected to represent each of these regions. Data on wind speed and direction (hourly means), precipitation, sunshine and air temperature (daily) measured at that location were provided for modelling the growth, dispersal and persistence of GM OSR on selected fields on the local level [57]. Linking each of the modelled sites with a map on German ecoregions [16], which integrates the spatial patterns of soils, elevation, vegetation and climate, the modelling results were anticipated by analogy reasoning to be valid for all those ecoregions which are represented by the modelling sites and, thus, could be spatially generalised for up-scaling [58].

\section{Case study 3: delineation and mapping of isolation zones}

Concerning the protection of non-target organisms that might be harmed due to GMP cultivation, a methodology was developed to classify the susceptibility/sensitivity of nature reserves [NSG] in Germany as being part of the receiving environment that might be affected due to GMP cropping in their vicinity. Within the joint research project 'Recommendations for isolation distances concerning the cultivation of genetically modified plants in the neighbourhood of protected areas' funded by the Federal Agency for Nature Conservation (BfN), possible risks for biocoenoses in protected areas were evaluated as well as measures which could mitigate or hinder negative effects [7]. According to Section 23 of the German Federal Nature Protection Law [BNatSchG], NSG are to protect nature and landscape properties by preserving and developing as well as by re-establishing existing biotopes of wild and endangered species. According to Section 34a of the BNatSchG, the use of GMP has to be accompanied by an environmental 

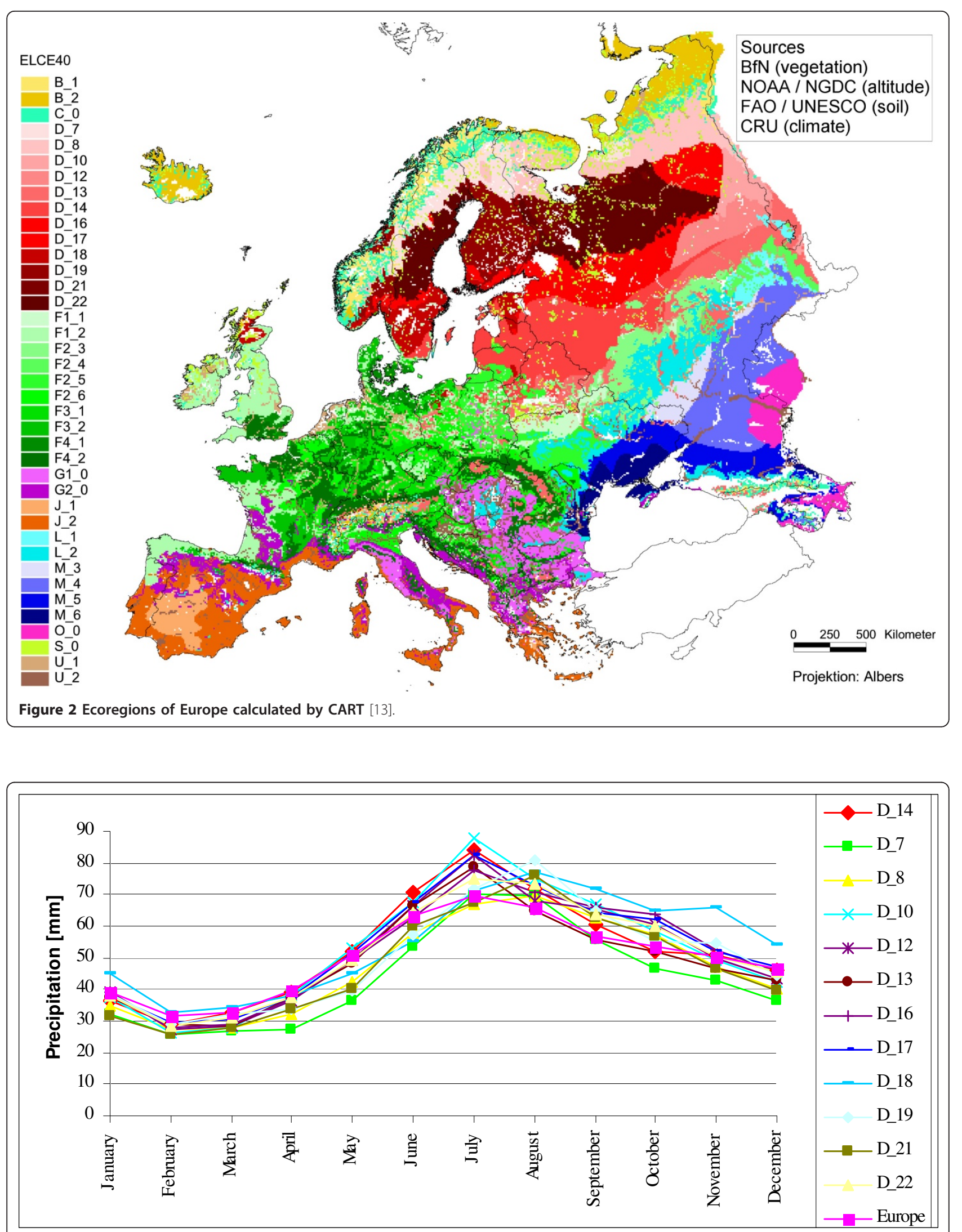

Figure 3 Annual course of precipitation (monthly means, 1961 to 1990) for some ecoregions in Europe [13]. 
impact analysis of possible risks like it has to be done in projects affecting the integrity of Flora-Fauna-Habitats (FFH) or European bird sanctuaries. In order to classify NSG according to their potential endangerment by GMP invasion, a methodology based on GIS techniques and statistical measures was developed. Additionally, it examined what implications would emerge when introducing different isolation distances concerning the cultivation of herbicide-resistant OSR and insect-resistant maize near protection areas [9]. Both should help in monitoring and modelling GMP impacts. Within a GIS environment, geometries of conservation areas, land use data (CORINE Landcover) [21], agricultural information on the district level (Easystat: Statistik Regional 1999) as well as a map of German ecoregions [16] were integrated. All NSG were classified with respect to geometric properties and different intensities of cultivation area in their vicinity. The classification was realised by calculating a geometric coefficient [GC] which described the ratio of the buffer zone and the NSG area in order to parameterize the risk of GMP invasion. The smaller and/or the narrower the NSG, the larger is the buffer zone, relatively, and the higher is the risk for GMP invasion. According to frequency analyses of the GC, three percentile classes (low/ medium/high) were derived. The cultivation area of maize and OSR cropping in the buffer zone around the NSG was expressed by a cultivation coefficient [CC]. This was calculated by adding up the area of maize and OSR cropland within a radius of $800 \mathrm{~m}$ (maize) and 4,000 $\mathrm{m}$ (OSR) around the NSG. Considering GMP cultivation in the future, these GMP fields are likely to be located in those regions where cultivation of conventional crops already has taken place. On the other hand, conventional maize or OSR fields might act as stepping stones to establish transgenes from GMP fields far off by cross-breeding with conventional stands, volunteers or ferals. Again, three percentile classes were built by frequency analyses. They describe the spectrum from a low to a high cultivation intensity of maize or OSR in the neighbourhood of each of the 7,338 NSG in Germany. The combination of GC and CC resulted in a total of nine risk categories $[\mathrm{RC}]$, describing the potential risk of endangerment by GMP cultivation in the vicinity of NSG. Areas with the highest risk were grouped in RC 9: Here, those NSG were assembled showing the smallest acreage and the highest cultivation rate of the respective crop (maize, OSR) in the neighbourhood of the NSG. With a numerical proportion of $7 \%$, those sites cover only $0.4 \%$ of the total area of all NSG. All NSG showing the highest CC values had a total proportion of $60 \%$ [9].

\section{Conclusions}

The GMP EM is an important element of the regulatory framework for GMO cultivation in Europe and needs to be conducted according to scientifically sound methods and quality criteria to generate data which have to be robust and conclusive. The choice of parameters, methods and experimental designs of the locations and the timeframe for GMP EM needs to ensure that adverse effects of GMP and their use can be detected reliably and as early as possible. To reach this end, guidelines such as that of the VDI [2] are needed in attempting to harmonise and standardise the GMP EM design.

The VDI [2] recognizes that the environmental effects of GMP may vary with the characteristics of different receiving environments in terms of e.g. climate, soils, land use patterns or geographic distribution of wild relatives of certain GMP. Therefore, data derived by ERA or EM should be collected in those regions which are representative for respective ecological and agronomic characteristics which potentially could influence the spread and impacts of GMP. Thus, spatially differentiated monitoring schemes are needed, in particular with regard to biodiversity (e.g. non-target organisms) and ecological processes and functions (e.g. soil functions) in which these organisms are involved. However, access to relevant geodata is a prevalent problem. In this context, the EU directive Infrastructure for Spatial Information in Europe [INSPIRE ${ }^{a}$ ] is an ambitious initiative to promote standardised data retrieval. In Germany, PortalU ${ }^{\mathrm{b}}$ is a first step to achieve the INSPIRE goals. However, the problem so far is that only few geodata sets are available, less of them being appropriate for GMP EM use. Exposure assessment is crucial for GMP EM, aiming to assess whether relevant parameters, e.g. certain non-target species, have to be in focus in the course of the monitoring. In combination with an effect assessment, the exposure assessment allows the evaluation of species which may be at risk. Geodata, ecological land classification, spatial estimation and GIS techniques in combination with dynamic modelling are fundamental to address effects on a landscape scale and long-term implications, to analyse and evaluate the appropriateness of existing monitoring programs or data for GMP EM, to design adaptations or extensions of the scope of GMP EM if they are inappropriate and to address the specific requirements for GMP EM.

\section{Endnotes}

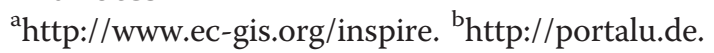

Authors' contributions

GS performed the GIS and statistical analysis. WS conceived the study, participated in its design and coordination, and drafted the manuscript. Both authors read and approved the final manuscript.

\section{Competing interests}

The authors declare that they have no competing interests. 
Received: 30 September 2011 Accepted: 30 January 2012

Published: 30 January 2012

\section{References}

1. European Community (EC): Directive 2001/18/EC of the European Parliament and of the Council of 12 March 2001 on the Deliberate Release into the Environment of Genetically Modified Organisms and Repealing Council Directive 90/220/EEC Brussels; 2001.

2. Association of German Engineers (VDI): Monitoring the Effects of Genetically Modified Organisms-Genetically Modified Plants. Basic Principles and Strategies. VDI 4330 Part 1 Düsseldorf; 2006.

3. Sanvido O, Widmer F, Winzeler M, Bigler F: A conceptual framework for the design of environmental postmarket monitoring of genetically modified plants. Environ Biosafety Res 2005, 4:13-27.

4. Züghart W, Breckling B: Konzeptionelle Entwicklung eines Monitoring von Umweltwirkungen transgener Kulturpflanzen, Teil 1 und 2. UBA-Texte 2003, 50/03:1-543.

5. Breckling B, Reuter H, Middelhoff U, Glemnitz M, Wurbs A, Schmidt G, Schröder W, Windhorst W: Risk indication of genetically modified organisms (GMO): modelling environmental exposure and dispersal across different scales: oilseed rape in Northern Germany as an integrated case study. Ecol Ind 2011, 11:936-941.

6. Graef F, Schmidt G, Schröder W, Stachow U: Determining ecoregions for environmental and GMO monitoring networks. Enviro Monit Assess 2005, 108:189-203

7. Menzel G, Lünsmann I, Middelhoff U, Breckling B, Schmidt G, Tillmann J, Schröder W, Filser J, Reuter H: Abstandsregelungen beim Anbau gentechnisch veränderter Pflanzen (GVP) in der Nähe von Schutzgebieten. Naturschutz und Biologische Vielfalt 2005, 10:1-227.

8. Reuter H, Middelhoff U, Graef F, Verhoeven R, Batz T, Weis M, Schmidt G, Schröder W, Breckling B: Information system for monitoring environmental impacts of genetically modified organisms. Environ Sci Pollut Res 2010, 17:1479-1490.

9. Schmidt G, Schröder W: GIS analyses on possible risks for nature reserves due to genetically modified crops. In Geospatial Crossroads @ Gl_Forum '08: Proceedings of the Geoinformatics Forum Salzburg. Edited by: Car A, Griesebner G, Strobl J. Heidelberg: Wichmann; 2008:240-245.

10. Schmidt G, Schröder W: Regionalisation of climate variability used for modelling the dispersal of genetically modified oil seed rape in Northern Germany. Ecol Ind 2011, 11:951-963.

11. Schmidt G, Kleppin L, Schröder W, Breckling B, Reuter H, Eschenbach C, Windhorst W, Höltl K, Wurbs A, Barkmann J, Marggraf R, Thiel M: Systemic risks of genetically modified organisms in crop production: interdisciplinary perspective. Gaia 2009, 18:119-126.

12. Olea RA: Geostatistics for Engineers and Earth Scientists Boston: Kluwer; 1999.

13. Hornsmann I, Pesch R, Schmidt G, Schröder W: Calculation of an Ecological Land Classification of Europe (ELCE) and its application for optimising environmental monitoring networks. In Geospatial Crossroads @ Gl_Forum '08: Proceedings of the Geoinformatics Forum Salzburg. Edited by: Car A, Griesebner G, Strobl J. Heidelberg Wichmann; 2008:140-151.

14. Pesch R, Schmidt G, Schröder W, Aden C, Kleppin L, Holy M: Development implementation and application of the WebGIS MossMet. In The Geospatial Web: How Geobrowsers, Social Software and the Web 2.0 are Shaping the Network Society. Edited by: Tochtermann K, Scharl A. London: Springer; 2007:191-200.

15. Pesch R, Schmidt G, Schröder W, Weustermann I: Application of CART in ecological landscape mapping: two case studies. Ecol Ind 2011, 11:115-122.

16. Schröder W, Schmidt G: Defining ecoregions as framework for the assessment of ecological monitoring networks in Germany by means of GIS and classification and regression trees (CART). Gate to EHS 2001, 1-9.

17. Schröder W, Schmidt G, Pesch R: Harmonization of environmental monitoring tools for examination of methodical comparability and spatial representativity. Gate to EHS 2003, 1-13.

18. Schröder W, Pesch R, Schmidt G: Analysis of climate change affecting German forests by combination of meteorological and phenological data within a GIS environment. Sci World 2007, 7:84-89.

19. Kleppin L, Schmidt G, Schröder W: Cultivation of GMO in Germany: support of monitoring and coexistence issues by WebGIS technology. Environ Sci Eur 2011, 23:1-11.

20. EIONET. [http://terrestrial.eionet.europa.eu/CLC2000],
21. Keil M, Kiefl R, Strunz G: CORINE Land Cover 2000-Germany. Final Report. Oberpfaffenhofen: German Aerospace Center, German Remote Sensing Data Center; 2005

22. EUROSTAT:[http://epp.eurostat.ec.europa.eu].

23. Climatic Research Unit (CRU) CL 2.0. [http://www.cru.uea.ac.uk/ timm/ grid/CRU_CL_2_0.html].

24. New M, Lister D, Hulme M, Makin I: A high-resolution data set of surface climate over global land areas. Clim Res 2002, 21:1-25.

25. Englert C, Pesch R, Schmidt G, Schröder W: Analysis of spatially and seasonally varying plant phenology in Germany. In Geospatial Crossroads @ Gl_Forum '08: Proceedings of the Geoinformatics Forum Salzburg. Edited by: Car A, Griesebner G, Strobl J. Heidelberg: Wichmann; 2008:81-89.

26. Oke TR: Boundary Layer Climates London: Routledge; 1987.

27. FAO Digital Soil Map of the World. [http://www.fao.org/nr/land/soils/ digital-soil-map-of-the-world/en].

28. FAO Harmonized World Soil Database v1.1. [http://www.fao.org/nr/land/ soils/harmonized-world-soil-database/en].

29. Bohn U, Hettwer C, Gollub G: Anwendung und Auswertung der Karte der natürlichen Vegetation Europas./Application and Analysis of the Map of the Natural Vegetation of Europe Bonn: BfN-Skripten (Bundesamt für Naturschutz); 2005

30. Secretariat of the Convention on Biological Diversity (SCBD): Cartagena Protocol on Biosafety to the Convention on Biological Diversity 2000, Montreal.

31. Secretariat of the Convention on Biological Diversity (SCBD): Global Biosafety: from Concepts to Action. Decisions Adopted by the First Meeting of the Conference of the Parties to the Convention on Biological Diversity Serving as the Meeting of the Parties to the Cartagena Protocol on Biosafety 2000, Montreal.

32. Vieno M, Toivonen $\mathrm{T}$ : Report of Analysis of Observational Biodiversity Information Needs and Products to Support the European Biodiversity Strategy and Parallel Activities Turku: European Network for Biodiversity Information (ENBI); 2005.

33. Gregory RD, Van Strien A, Vorisek P, Meyling AWG, Noble DG, Foppen RPB Gibbons DW: Developing indicators for European birds. Philos Trans Roy Soc B Biol Sci 2005, 360:269-288.

34. Thomas JA: Monitoring change in the abundance and distribution of insects using butterflies and other indicator groups. Philos Trans $R$ Soc $B$ Biol Sci 2005, 360:339-357.

35. EuMon database. [http://eumon.ckff.si/monitoring/search.php].

36. Schmeller DS, Henry PY, Julliard R, Clobert J, Gruber B, Dziock F, Lengyel S, Nowicki P, Déri E, Budrys E, Kull T, Tali K, Bauch B, Settele J, van Swaay C, Kobler A, Babij V, Papastergiadou E, Henle K: Advantages of volunteerbased biodiversity monitoring in Europe. Conserv Biol 23:307-316.

37. Global Biodiversity Information Facility (GBIF). [http://www.gbif.org].

38. European Forest Genetic Resources Programme (EUFORGEN). [http:// www.euforgen.org/distribution maps.html].

39. DIVA-GIS. [http://www.diva-gis.org].

40. International Potato Center (CIP). [http://www.cipotato.org].

41. FloraWeb. [http://www.floraweb.de]

42. Bundesministerium für Umwelt, Naturschutz und Reaktorsicherheit (BMU): Umweltbeobachtung. Stand und Entwicklungsmöglichkeiten 2000, Bonn

43. Keune H, Mandry P: Harmonization of environmental data. The requirements for developing a consistent view of the environment world-wide. In Global Monitoring of Terrestrial Ecosystems. Edited by: Schröder W, Fränzle O, Keune H, Mandry P. Berlin, Ernst 1996:51-56.

44. Craig W, Tepfer M, Degrassi G, Ripandelli D: An overview of general features of risk assessments of genetically modified crops. Euphytica 2008, 164:853-880.

45. Cao Y, Williams DD, Larsen DP: Comparison of ecological communities: the problem of sample representativeness. Ecol Monogr 2002, 72:41-56.

46. Tirler W, Donega M, Voto G, Kahr G: Quick evaluation of long term monitoring samples and its representativeness. Organohalogen Compounds 2003, 60:509-512.

47. Bühler C: Biodiversity monitoring in Switzerland: what can we learn for general surveillance of GM crops? J Verbr Lebensm 2006, 1:37-41.

48. Leigh RA, Johnston AE: Long-term Experiments in Agricultural and Ecological Sciences: Proceedings of a Conference to Celebrate the 150th Anniversary of Rothamsted Experimental Station, Held at Rothamsted, 14-17 July 1993 Wallingford: CAB International; 1994.

49. Stein A, Ettema C: An overview of spatial sampling procedures and experimental design of spatial studies for ecosystem comparisons. Agric Ecosyst Environ 2003, 94:31-47. 
50. Wilkinson MJ, Davenport IJ, Charters YM, Jones AE, Allainguillaume J, Butler HT, Mason DC, Raybould AF: A direct regional scale estimate of transgene movement from genetically modified oilseed rape to its wild progenitors. Mol Ecol 2000, 9:983-991.

51. Hastings DA, Dunbar PK, Elphingstone GM, Bootz M, Murakami H, Maruyama H, Masaharu H, Holland P, Payne J, Bryant NA, Logan TL, Muller J-P, Schreier G, Macdonald JS: The Global Land One-kilometer Base Elevation (GLOBE) Digital Elevation Model, Version 1.0 Boulder: National Oceanic and Atmospheric Administration, National Geophysical Data Center; 1999.

52. Ward JH: Hierarchical grouping methods to optimise an objective function. J Am Stat Assoc 1963, 58:236-244.

53. Knapp PA, Grissino-Mayer HD, Soule PT: Climatic regionalization and the spatio-temporal occurrence of extreme single-year drought events (1500-1998) in the Interior Pacific Northwest, USA. Quaternary Res 2002, 58:226-233.

54. Shwartz M, Payne SMC, Restuccia JD, Ash AS: Does it matter how small geographic areas are constructed? Ward's algorithm versus the plurality rule. Health Serv Outcomes Res Methodol 2001, 2:5-18.

55. Zhou Y, Narumalani S, Waltman WJ, Waltman SW, Palecki MA: A GIS based spatial pattern analysis model for ecoregion mapping and characterization. Int J Geogr Inform Sci 2003, 17:445-462.

56. Glemnitz M, Wurbs A, Roth R: Derivation of regional crop sequences as an indicator for potential GMP dispersal on large spatial scales. Ecol Indicat 2011, 11:964-973.

57. Middelhoff $U$, Reuter $H$, Breckling B: GeneTraMP, a spatio-temporal model of the dispersal and persistence of transgenes in feral, volunteer and crop plants of oilseed rape and related species. Ecol Indicat 2011, 11:974-988.

58. Reuter H, Schmidt G, Schröder W, Middelhoff U, Pehlke H, Breckling B: Regional distribution of genetically modified organisms (GMOs)-upscaling the dispersal and persistence potential of herbicide resistant oilseed rape (Brassisca napus). Ecol Indicat 2011, 11:989-999.

doi:10.1186/2190-4715-24-6

Cite this article as: Schröder and Schmidt: Overview of principles and implementations to deal with spatial issues in monitoring

environmental effects of genetically modified organisms. Environmental Sciences Europe 2012 24:6.

\section{Submit your manuscript to a SpringerOpen ${ }^{\mathcal{O}}$ journal and benefit from:}

- Convenient online submission

- Rigorous peer review

- Immediate publication on acceptance

- Open access: articles freely available online

- High visibility within the field

- Retaining the copyright to your article

Submit your next manuscript at $\gg$ springeropen.com 